\title{
Double-objective optimization-based firefly algorithm of a stand-alone photovoltaic/ water pumping system for water supply in rural and remote areas: a case study
}

\author{
Ruben Zieba Falama ${ }^{1,2^{*}} \mathbb{0}$, Hamadou Bakari ${ }^{2}$ and Virgil Dumbrava ${ }^{3}$
}

${ }^{*}$ Correspondence:

rubenziebafalama@gmail.

com

${ }^{1}$ Faculty of Mines

and Petroleum Industries,

University of Maroua, P.O.

Box 46, Maroua, Cameroon

Full list of author information

is available at the end of the

article

\begin{abstract}
A techno-economic study of a stand-alone PV water pumping system for water supply is done in this paper. An optimal design of the system is realized thanks to a doubleobjective optimization based on a proposed operational strategy of the system and on firefly algorithm (FA). The two objective functions simulated simultaneously using FA are: the function defining the cost of water (COW) and the function which defines the loss of water supply probability (LWSP). The system is designed to supply water to around 328 households in Cameroon, each composed by an average of six (06) persons. For different LWSP, the double-objective simulation determines the optimal configurations of the system with their related cost. The optimal and reliable (LWSP of 0\%) system configuration obtained is composed by a number of $7 \mathrm{PV}$ modules, a reservoir volume of $98.4 \mathrm{~m}^{3}$ with 2 days autonomy, a total dynamic head of $40 \mathrm{~m}$, and a pump power of around $1 \mathrm{~kW}$. The related COW corresponding to this configuration is $0.1185 \$ / \mathrm{m}^{3}$, and the total investment cost is $27,506 \$$. The sensitivity analysis of the system revealed that the PV size, the volume of reservoir storage, and the efficiency of the pump influence the system both technically and economically, whereas the total dynamic head only influences the system economically. The validation of the optimized system has been done by comparison with manufacturer datasheets. It is demonstrated in this paper that the techno-economic analysis of energy systems based on multi-objective optimization using firefly algorithm is a powerful tool for decision-making.
\end{abstract}

Keywords: Techno-economic study, Optimal design, FA, COW, LWSP

\section{Introduction}

On the threshold of this third millennium, it turns out that one among five inhabitants of the earth does not have access to suitable drinking water. According to the World Health Organization (WHO), more than five million people die each year from diseases caused by unsuitable water for human consumption. Despite national and international efforts to access to drinking water for populations, the problem still persists in author(s) and the source, provide a link to the Creative Commons licence, and indicate if changes were made. The images or other third party material in this article are included in the article's Creative Commons licence, unless indicated otherwise in a credit line to the material. If material is not included in the article's Creative Commons licence and your intended use is not permitted by statutory regulation or exceeds the permitted use, you will need to obtain permission directly from the copyright holder. To view a copy of this licence, visit http:// creativecommons.org/licenses/by/4.0/. 
developing countries, especially those of Africa, and is worsening with the fast growth of the population.

Surface water is easily accessible, but its quality may not be suitable for human consumption, agriculture, or industry. Before being used for consumption, surface water needs to be treated. Groundwater, on the other hand, is directly drinkable and must therefore be exploited. To be brought to the surface and used for human and animal consumption, groundwater needs to be pumped. In order to obtain large quantities of water, electric pumps are used and thus require a reliable source of energy.

Communities that are connected to the local electricity grid use this energy to power hydraulic pumps. These communities also often use the diesel generator for water pumping. For communities that are not connected to the grid, the diesel generator is mainly used. However, these methods of using electricity to pump water are often very expensive and harmful to the environment like the diesel generator. It is therefore important to look for alternative energy sources for water pumping. Photovoltaic solar water pumping is presented as a promising alternative solution to meet this demand. Indeed, several governments and international organizations are using photovoltaic water pumping to help rural and isolated populations. The sale of water is organized in this case to cover the costs of the maintenance of the system. Many individuals, public services, even in urban areas, are also now using photovoltaic water pumping for water supply in various applications. Because of their importance, many researches are carried out on photovoltaic water pumping systems concerning the improvement in their performance [1-6], their optimal sizing [7-11], the economic and environmental aspect [12-15], the tracking of the maximum power point [16-19]. The current study is interested by the optimal sizing of these systems regarding their reliability and the economic aspects. Below are presented some previous works carried out on solar water pumping systems.

Ibrahim et al. [20] developed a computer program for the design of a solar water pumping system. This program, based on mathematical modeling, allows the complete sizing of the system components. The economic analysis they did in their study revealed that solar water pumping is much more accessible than diesel generator-based pumping. The model they developed could be of great importance to both designers and users.

Muhsen et al. [21] carried out a study on the techno-economic analysis and the optimal sizing of an autonomous photovoltaic water pumping system for the water supply of a small village. A numerical approach based on an iterative method was used for this purpose. The optimal configuration of the system is determined through a simulation based on the minimization of two objective functions, one of which takes into account the technical aspect and the other the economic aspect. The determined system parameters are the size of the water storage tank and the total number of PV modules. For a population of 120 people with a daily water requirement estimated at $30 \mathrm{~m}^{3}$, the optimal configuration consists of 20 modules of $120 \mathrm{~W}$ and $52 \mathrm{~m}^{3}$ as the maximum capacity of the storage tank.

Chennaif et al. [22] carried out a study on the optimal sizing of the components of a photovoltaic water pumping system applied to irrigation. This optimal sizing is obtained thanks to a techno-economic analysis based on the "Electric system cascade analysis" method. Several system configurations are taken into account. The two optimization criteria considered are the "loss of water supply probability" and the "life cycle cost." The 
results obtained show that for a continuously variable daily water requirement in the study site considered, the optimal configuration of the system consists of $23 \mathrm{PV}$ modules of $250 \mathrm{~W}_{\mathrm{c}}$ and a water storage tank of $610 \mathrm{~m}^{3}$.

Olcan [23] has proposed a multi-objective analytical method for the optimal sizing of components of stand-alone photovoltaic water pumping systems for irrigation in remote areas. The reliability of the most optimal configuration is identified by its ability to minimize the deficiency of the power supply probability. The minimization of the life cycle cost is also considered as a selection criterion in the proposed model. The proposed analytical model has been validated by a numerical model.

A design optimization of solar PV water pumping for various applications has been performed by Sharma et al. [24] based on mathematical modeling and PVsyst 5.52 software simulation tool. This optimal design takes into account both technical and economic aspects. The results obtained in their study prove the performance of PVsyst software for optimal analysis of PV systems.

Multi-objective optimization appears as a powerful tool for the optimal sizing of stand-alone PV and hybrid systems [11, 25-32]. The effectiveness and performance of this kind of optimization are related to the optimization algorithm program used for simulation. Recently the multi-objective optimization using evolutionary algorithms appears as promising optimization technique for energy systems [11, 25-31]. The most used evolutionary algorithms for energy systems optimization are genetic algorithm and particle swarm optimization methods [11]. Multi-objective optimization based on the Firefly algorithm $[33,34]$ for the design and analysis of energy systems has not yet received a significant attention from researchers. However, this algorithm having a good and rapid convergence is adapted for multi-objective optimization [35, 36].

A double-objective optimization using firefly algorithm is performed in this work to determine the optimal and reliable configuration of photovoltaic water pumping system that satisfies the load demand (water demand) at all the times of the year. One of the particularities of the proposed design method is that all the sizes of the system components are determined by simulation including the pump nominal power. The sizes of the main system components (Photovoltaic generator, reservoir water storage, and pump) are obtained thanks to the optimized variables which they are related based on mathematical equations.

\section{System components and site of study}

\section{System components}

The operation of a photovoltaic water pumping requires the design and the implementation of its production system. A photovoltaic water pumping system can have different configurations according to the users' priorities. However, in order to be adopted, a configuration must be able to meet some criteria related to the cost and its capacity to respond efficiently to water demand, even in critical climatic conditions. The main components of the studied stand-alone photovoltaic water pumping system are: the PV generator, the water storage system (tank), and the pump. This study is only limited on the water production and does not include the distribution. Also the energy storage is not included in the present system. When the PV array is unable to provide electrical energy to the pump or when the pump is off (especially during the night), the water is 
provided to users thanks to the stored water in the tank during the pump working time. A schematic representation of the studied system is given in Fig. 1.

\section{Description and location of the studied site}

Waza is an area of Far-Nord region of Cameroon, located at $11^{\circ} 21^{\prime} \mathrm{N}$ latitude and $14^{\circ}$ $31^{\prime} \mathrm{E}$ longitude. A distance of about one hundred and twenty kilometers separates this locality from the Maroua town. It is characterized by a hot and dry climate. Some reasons can justify the choice of Waza as the site of study. One of the reasons is because this locality faces the problem of lack of water. Another reason that can justify the choice of Waza for this study is because there is an international touristic site in Waza which hosts tourists and researchers from everywhere and every year, and then requires the constant availability of suitable drinking water. Photovoltaic water pumping could be for Waza, a reliable and sustainable solution, due to the great solar potential in this locality. Figure 2 presents the localization of Waza on the geographic map.

The evaluation of the solar energy potential is one of the main aspects to consider before to install a PV system. The ambient temperature also has an influence on the photovoltaic energy production. The average solar radiation and the average ambient temperature of the site of Waza for different months of the year are presented in Table 1.

\section{Methods}

\section{System modeling}

\section{Pump power modeling}

It is assumed in this study that the PV/water pumping system is designed to supply water to about 328 households. Each household is composed by an average of 6 persons, and the water demand (for cooking, drinking, washing...) for each person is considered to be $25 \mathrm{~L}$ per day. Thus, the total volume of the water demand $\left(V_{\text {demand }}\right)$ is $49200 \mathrm{~L} /$ day or $49.200 \mathrm{~m}^{3} /$ day. By setting the pump running time to $8 \mathrm{~h} /$ day, then the water flow rate will be $Q_{\text {pump }}=6.15 \mathrm{~m}^{3} / \mathrm{h}$ or $0.1025 \mathrm{~m}^{3} / \mathrm{s}$. Note that the pump is only working on the

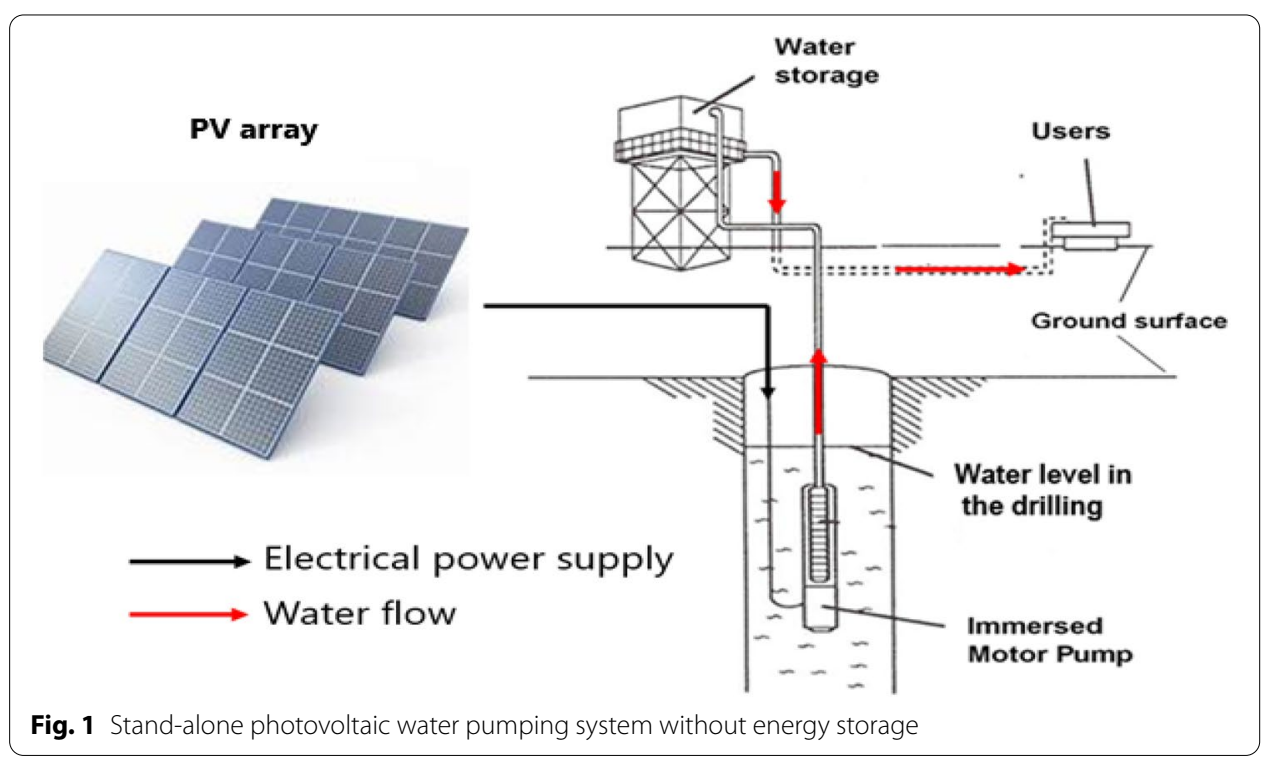




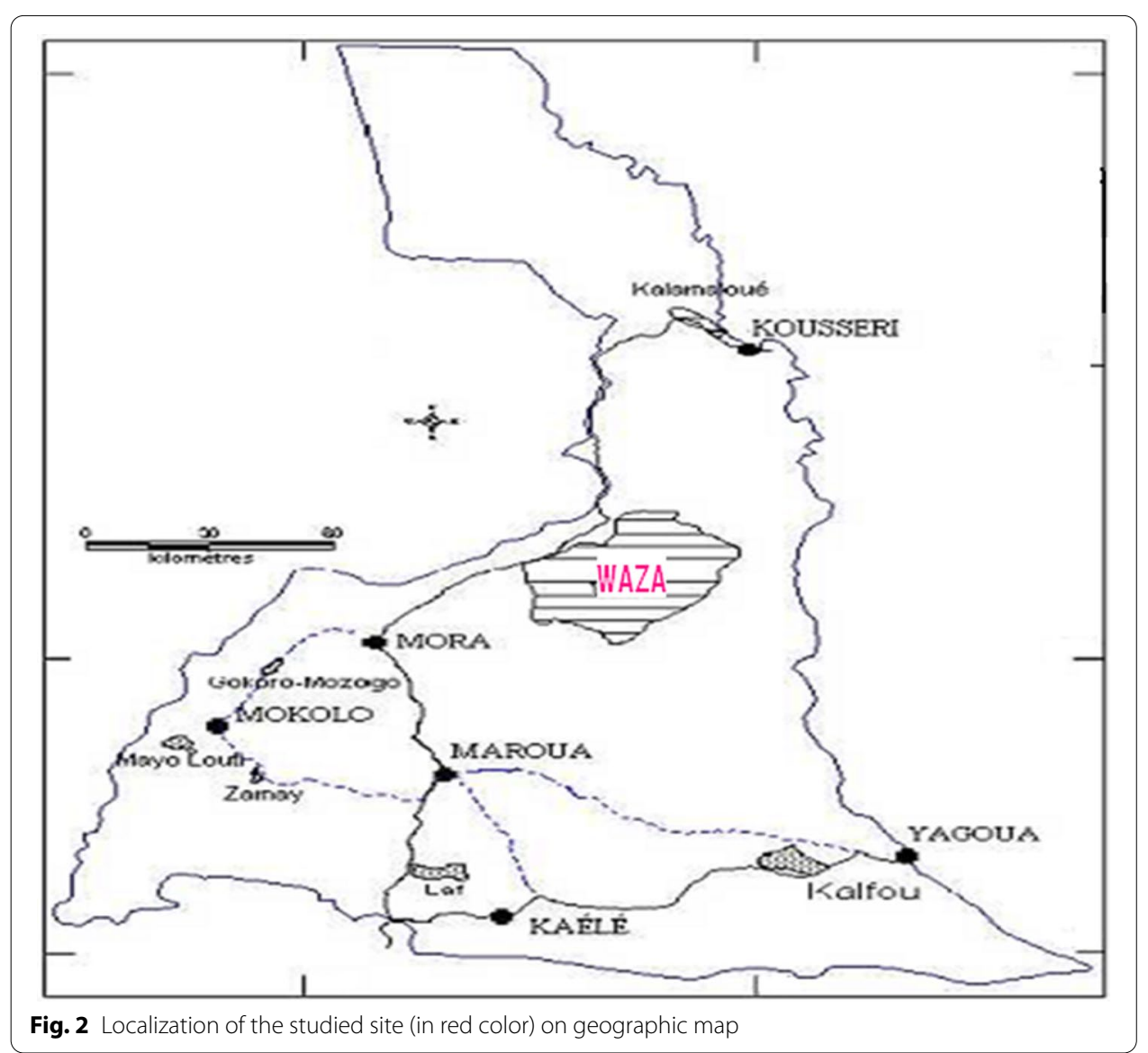

Table 1 Solar radiation and ambient temperature of Waza [37]

\begin{tabular}{lcc}
\hline Month of the year & Solar radiation $\left.\mathbf{( k W h} / \mathbf{m}^{\mathbf{2}}\right)$ & $\begin{array}{l}\text { Ambient } \\
\text { temperature } \\
\left({ }^{\circ} \mathbf{C}\right)\end{array}$ \\
\hline January & & 24.1 \\
February & 187.7 & 27.3 \\
March & 190.92 & 33.4 \\
April & 195.31 & 33.9 \\
May & 204.16 & 32 \\
June & 187.97 & 30.1 \\
July & 155.55 & 27.2 \\
August & 161.99 & 26.2 \\
September & 169.47 & 27.4 \\
October & 181.64 & 29.8 \\
November & 192.54 & 30 \\
December & 180.68 & 26.1 \\
\hline
\end{tabular}

day since the energy storage (like batteries for example) is not included in the system. The sizing of the solar pump is closely related to the water flow rate. The pump power is given by 


$$
P_{\text {pump }}(W)=\frac{\rho g H_{\mathrm{t}} Q_{\text {pump }}}{\eta}
$$

Since the pump power is a function of the total dynamic head $\left(H_{\mathrm{t}}\right)$ which is one of the variables to be optimized in this study, the pump nominal power is also optimized according to this parameter.

The total daily nominal energy requested to pump the daily demanded quantity of water is determined by

$$
E_{\text {pump }}(W h)=P_{\text {pump }}(W) \times \text { Pump daily running time (hours) }
$$

\section{PV output calculation}

The PV power output is calculated by the equation

$$
E_{\mathrm{pv}}(\mathrm{kWh})=N_{\mathrm{pv}} \cdot P_{\mathrm{Pv}, \mathrm{ref}}(W) \cdot\left(\frac{G\left(\mathrm{kWh} / \mathrm{m}^{2}\right)}{G_{\mathrm{ref}}\left(\mathrm{W} / \mathrm{m}^{2}\right)}\right) \cdot\left[1-\alpha\left(T_{\mathrm{c}}-T_{\mathrm{c}, \mathrm{ref}}\right)\right]
$$

where

$$
T_{c}=T_{a}+\frac{\mathrm{NOCT}-20}{G_{\mathrm{NOCT}}\left(\mathrm{kWh} / \mathrm{m}^{2}\right)} \cdot G\left(\mathrm{kWh} / \mathrm{m}^{2}\right)
$$

$P_{\mathrm{pv}, \mathrm{ref}}$ is the power of the PV generator at the maximum point in standard test conditions given by the constructor.

\section{Water storage subsystem modeling}

The volume of the water tank is calculated by

$$
V_{R \max }=N_{\mathrm{ad}} \cdot V_{\mathrm{demand}}
$$

$N_{\text {ad }}$ is the number of autonomy days of the reservoir and $V_{\text {demand }}$ is the total volume of the daily water demand.

\section{Multi-objective optimization and problem formulation}

A multi-objective optimization technique is performed in this study to determine the optimal key parameters of the system while minimizing the cost and ensuring an efficient satisfaction of the load requirement (here the water demand). This study focused on a double-objective optimization based on firefly algorithm.

Firefly optimization algorithm (FA) is among the recent metaheuristic algorithms. It is a bio-inspired algorithm developed by Yang [16-19]. Fireflies are small, winged beetles able of producing a cool flashing light for mutual attraction. Females can mimic the light signals of other species to attract males to capture and eat. Fireflies have a capacitor-like mechanism, which slowly discharges until a certain threshold is reached, they release energy in the form of light. The phenomenon repeats itself cyclically. This algorithm is designed to solve optimization problems in many practical areas. The algorithm is based on the principle of attraction between fireflies and simulates the behavior of a swarm of fireflies in nature, which gives it many similarities 
with other metaheuristics algorithms based on the collective intelligence of the group, such as the PSO algorithm (Particle Swarm Optimization), the bee colony optimization algorithm $(\mathrm{ABC})$.

In the firefly algorithm (FA), there are some points that are taken into account: (1) All fireflies are such unisexual that one firefly will be attracted to others independently of their gender, (2) The attractiveness is proportional to their brightness and decreases as the distance between them increases, (3) The brightness of the fireflies is determined according to an objective function (to be optimized). The main steps of firefly algorithm include: the initialization, the attractiveness and distance, the generation of the next generation, the iterative computing, and the termination.

Basic firefly algorithm considers that the position of a firefly $a$ is given by $X_{i}=\left(x_{i, 1}\right.$, $\left.x_{i, 2}, \ldots, x_{i, N}\right)$, where $X_{i}$ is a $N$-dimensional vector. The light intensity or the brightness of this firefly is given by

$$
I_{i}=f\left(X_{i}\right)
$$

where $f\left(X_{i}\right)$ is the objective function to optimize.

Another firefly with a light intensity greater than the light intensity of firefly $i$ will attract the firefly $I$ that will move toward his position. If $j$ is a firefly with a brightness greater than the brightness of $i$, then the attractiveness is given by

$$
\beta_{i j}=\beta_{0} e^{-\gamma s_{i j}^{2}}
$$

In Eq. (7), $\gamma$ is the light absorption coefficient, $\beta_{0}$ is the attractiveness at $s_{i j}=0, s_{i j}$ is the distance between the fireflies $i$ and $j$, given by

$$
s_{i j}=\sqrt{\sum_{k=1}^{N}\left(x_{i, k}-x_{j, k}\right)^{2}}
$$

The updating formula for the firefly $i$ to move toward firefly $j$ is given by

$$
X_{i}^{\text {updated }}=X_{i}^{\text {initial }}+\beta_{0} e^{-\gamma s_{i j}^{2}}\left(X_{j}^{\text {initial }}-X_{i}^{\text {initial }}\right)+\alpha \varepsilon
$$

where $X_{i}^{\text {updated }}$ and $X_{i}^{\text {initial }}$ are the updated and the initial position of the firefly $i$, respectively, $X_{j}^{\text {initial }}$ is the initial position of the firefly $j, \alpha$ is the randomization parameter having a value in the interval $[0,1]$, and $\varepsilon$ is a random number drawn from a Gaussian distribution or a uniform distribution.

The flowchart of a basic FA algorithm is presented in Fig. 3.

The purpose of a multi-objective firefly optimization used in this work is to find a set of vector of decision variables satisfying constraints and optimizing the objectives functions. Mathematically the used multi-objective firefly optimization algorithm aims to

Find vector : $X=\left(x_{1}, x_{2}, \ldots, x_{N}\right)$.

By minimizing : $F(X)=\left(f_{1}(X), f_{2}(X), \ldots, f_{m}(X)\right)$ 


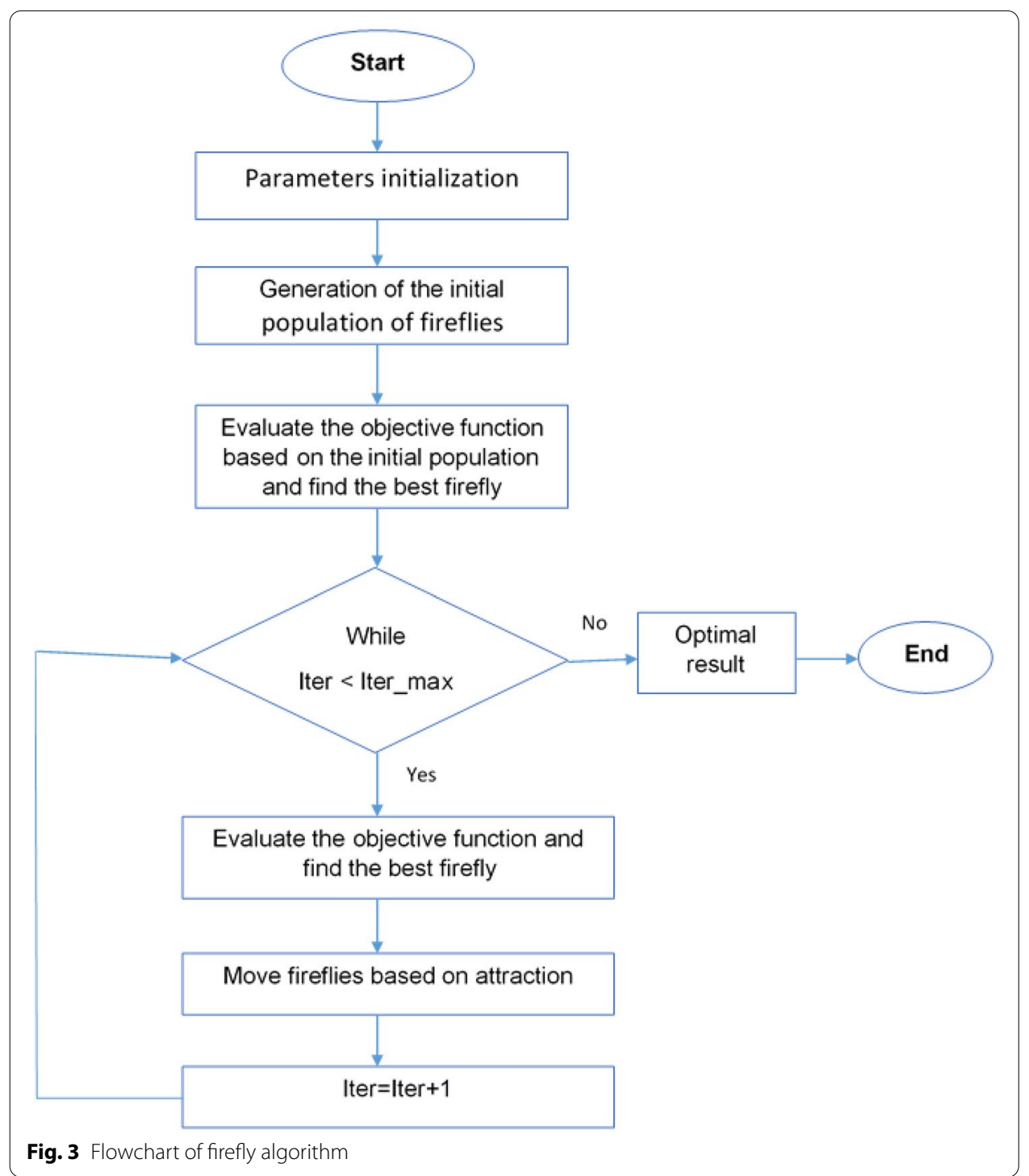

And respecting the constraints of the problem.

$X$ is the vector decision variables, $F$ is the objective functions vector, $m$ is the number of objectives function to optimize.

In multi-objective firefly optimization, the first possibility is to combine the objective functions in one single objective function and compute the algorithms without much modifications. The second possibility which is used in the present study is to produce Pareto optimal front directly by extending the firefly algorithm.

Let us consider a feasible solutions $X$. If there is not another existing solution $X^{\prime}$ in the feasible solutions set satisfying the conditions of Eq. (12), then $X$ is called a Pareto optimal solution of the multi-objective problem. $X^{\prime}$ is called a dominated solution $\left(X^{\prime}\right.$ $<X$ ). The Pareto optimal frontier constituted by the Pareto optimal solutions is very useful for decision-making. 


$$
\begin{cases}f_{i}\left(X^{\prime}\right) \leq f_{i}(X), & i=1, \ldots, m \\ f_{j}\left(X^{\prime}\right)<f_{j}(X), & j=1, \ldots, m\end{cases}
$$

\section{The objective functions}

Firefly algorithm is used in the present work to minimize two objective functions. The first objective function defined by Eq. (13) is based on the cost of water (COW). It is determined from the cost of the system components and the total volume of water demand over one year.

$$
\text { Objective }(1)=\operatorname{COW}\left(\$ / \mathrm{m}^{3}\right)=\frac{\left(\text { Cost }_{\mathrm{PV}}+\text { Cost }_{\text {reservoir }}+\text { Cost }_{\text {pump }}\right) \cdot \mathrm{CRF}}{\text { Annual volume of water demand }}
$$

where

$$
\mathrm{CRF}=\frac{\mathrm{i}(1+\mathrm{i})^{\gamma}}{(1+\mathrm{i})^{\gamma}-1}
$$

and

$$
i=\frac{i^{\prime}-f}{1+f}
$$

In the above equations, CRF is the capital recovery factor, $i$ is the interest rate, $i^{\prime}$ is the nominal interest rate, $\mathrm{f}$ is the annual inflation rate, $\gamma$ is the system lifetime (years).

The second objective function is used to evaluate the system reliability based on the loss of water supply probability (LWSP) index. In the case of this study, this index is defined by Eq. (16).

$$
\text { Objective }(2)=\operatorname{LWSP}(\%)=\frac{\sum_{t=1}^{365} \text { days }\left[V_{R}(t)<V_{\text {demand }}(t)\right]}{365}
$$

Table 2 presents the details concerning the cost and the lifetime of the key components of the studied system used for simulation and matching with Cameroonian market. The given cost for each component includes installation, operation, and maintenance. For the components to be replaced at the end of their lifetime, their replacement costs are the same as their initial costs. The cost of the reservoir is based on the cost functions defined in Refs. [7, 8].

Table 2 Cost of key components

\begin{tabular}{llll}
\hline Designation & Unit & Cost (\$) & $\begin{array}{l}\text { Lifetime } \\
\text { (years) }\end{array}$ \\
\hline PV array & W & 1.5 & 25 \\
Reinforced concrete (reservoir) & $\mathrm{m}^{3}$ & 170 & 35 \\
Motor pump & $\mathrm{kW}$ & 2770 & 10 \\
\hline
\end{tabular}




\section{Constraints of the problem}

The constraint on the reliability of the system involves that for the best optimal system configuration,

$$
\operatorname{LWSP}(\%)=0
$$

The constraints on the number of PV modules, the number of autonomy days of the reservoir storage, and the total dynamic head are expressed, respectively, by Eqs. (18), (19), and (20).

$$
\begin{aligned}
& N_{\mathrm{pv}, \text { min }} \leq N_{\mathrm{pv}} \leq N_{\mathrm{pv}, \text { max }} \\
& N_{\mathrm{ad}, \text { min }} \leq N_{\mathrm{ad}} \leq N_{\mathrm{ad}, \text { max }} \\
& H_{t, \text { min }} \leq H_{t} \leq H_{t, \text { max }}
\end{aligned}
$$

The constraints on the generated PV power, the reservoir storage, and the pump running power are expressed, respectively, by Eqs. (21), (22), and (23).

$$
\begin{aligned}
& E_{\mathrm{pv}}(t) \geq E_{\text {pump }}(t) \\
& V_{\text {supply }}(t) \geq V_{\text {demand }}(t) \\
& E_{\text {pump,min }} \leq E_{\text {pump }}(t) \leq E_{\text {pump, max }}
\end{aligned}
$$

\section{Operational strategy and system optimization}

The water is pumped from a borehole by using a submersible pump. Important parameters to consider in sizing a pumping/water storage system are the type and the size of the pump, the height difference between the pumped water level and the maximum water level in the tank (total dynamic head), the maximum volume of the water storage tank. The pump operates thanks to the energy directly supplied by the PV panels.

The reliability of the system is based on his ability to meet the water demand at all the days of the year. The main inputs parameters for simulation are the meteorological data (irradiance and ambient temperature), and the daily water demand. The variables to be determined through the simulation process based on the operational strategy of the studied system are: the number of PV modules $\left(N_{\mathrm{PV}}\right)$, the number of autonomy days of the reservoir $\left(N_{\mathrm{ad}}\right)$, and the total dynamic head $\left(H_{\mathrm{t}}\right)$.

In the defined operational strategy, the PV power (energy) production is determined for each time interval corresponding to the given meteorological data. The generated power is used to run the motor pump according to the availability of the energy resource. The pump can only operate if the electrical energy delivered by the PV generator is at least equal to the minimum energy required to run it. Indeed, the permissible range of operating power (respectively, energy) of the pump is defined by: $P_{\text {pump, min }}=0.6 \times P_{\text {pump }}$ $\left(E_{\text {pump } \min }=0.6 \times E_{\text {pump }}\right)$, and $P_{\text {pump } \max }=1.2 \times P_{\text {pump }}\left(E_{\text {pump } \max }=1.2 \times E_{\text {pump }}\right)$. 


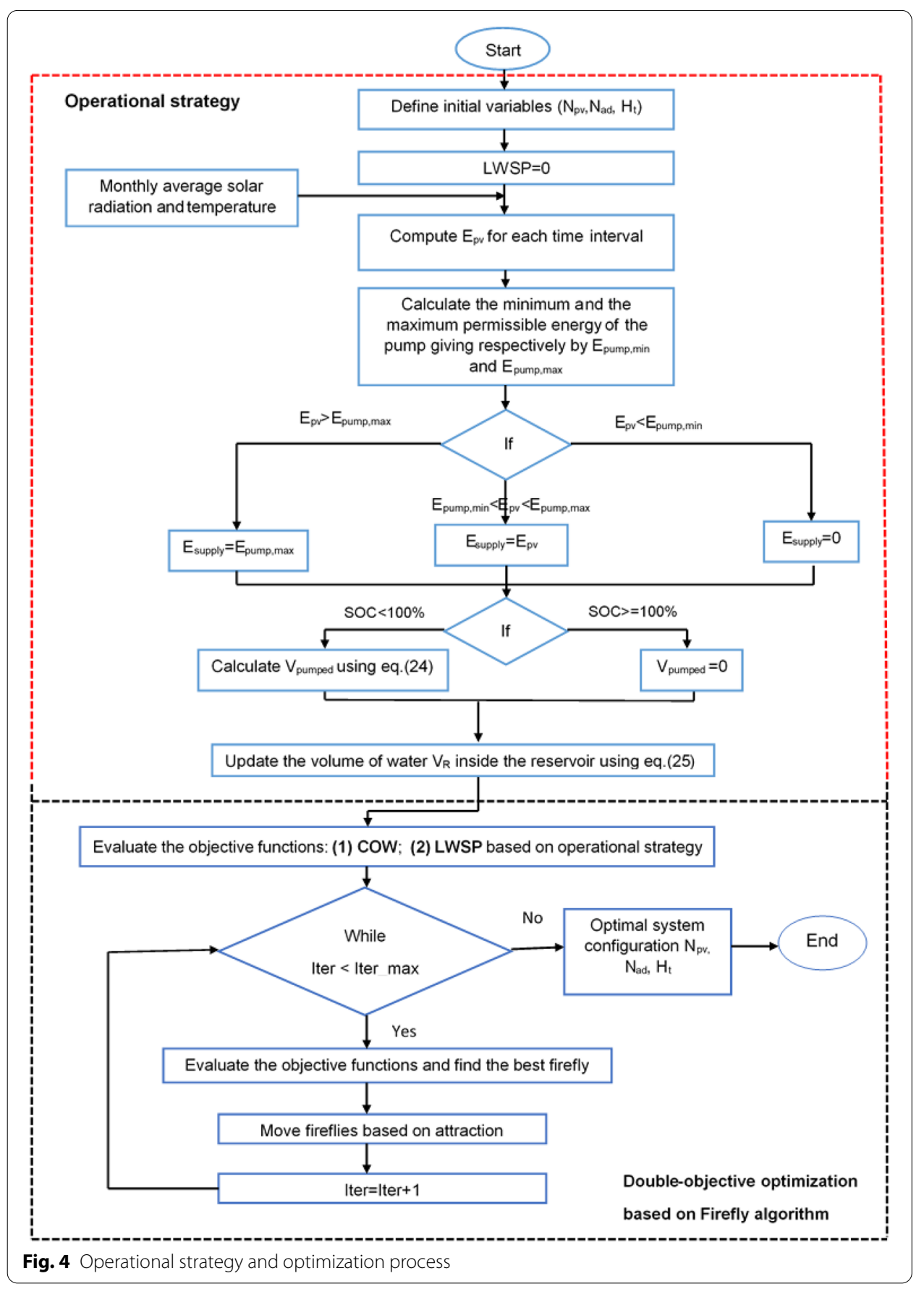

The detailed description of the operational strategy of the studied system associated with the optimization process is given in Fig. 4. In this description, the following points are explained:

- The daily pumped water at day $t(t$ is the number of the day) and the volume of water in the storage reservoir at the day $t$ are determined, respectively, by Eqs. (24) and (25). The state of charge of the water tank at each moment is given by Eq. (26). 


$$
\begin{aligned}
& V_{\text {pumped }}(t)=\frac{\eta \cdot E_{\text {supply }}(t)}{\rho g H_{\mathrm{t}}} \\
& V_{\mathrm{R}}(t+1)=V_{\mathrm{R}}(t)+\left(V_{\text {pumped }}(t)-V_{\text {demand }}(t)\right) \\
& \operatorname{SOC}(\mathrm{t})=\frac{\mathrm{V}_{\mathrm{R}}(\mathrm{t})}{\mathrm{V}_{\mathrm{R}_{\max }}}
\end{aligned}
$$

- The PV energy delivered by the generator is determined for each time interval, here 1 day;

- If the PV energy is greater than the maximum permissible energy of the pump $\left(E_{\mathrm{pv}}(t)>E_{\mathrm{pump}, \max }(t)\right)$, then the energy supplied to the pump is equal to his maximum permissible energy, i.e., $E_{\text {supply }}(t)=E_{\text {pump, max }}(t)$. The excess PV energy is lost.

- If the PV energy delivered is in the permissible energy range, that is to say, between $E_{\mathrm{pump}, \min }$ and $E_{\mathrm{pump}, \max }\left(E_{\mathrm{pump}, \min }(t)<E_{\mathrm{pv}}(t)<E_{\mathrm{pump}, \max }(t)\right)$, then the operating energy of the pump is equal to the energy delivered by the generator, i.e., $E_{\text {supply }}(t)=E_{\mathrm{pv}}(t)$.

- If the PV energy delivered is less than the minimum permissible energy $\left(E_{\mathrm{pv}}(t)<E_{\mathrm{pump}, \min }(t)\right)$, then the pump will be off; ie $E_{\text {supply }}(t)=0$.

- The state of charge of water (SOC) in the tank (level of water in the tank) is determined for each time interval according to Eq. (26). If the volume of the water in the tank is greater than (or equal to) the maximum volume of the tank, the pump will stop to work until the next time interval and will restart if the volume of the water in the tank decreases and if the energy demand is met. The optimal combination of $N_{\mathrm{pv}}, N_{\mathrm{ad}}$, and $H_{\mathrm{t}}$ satisfying the desired LWSP and having at the same time

Table 3 Pseudo-code of the double-objective firefly optimization

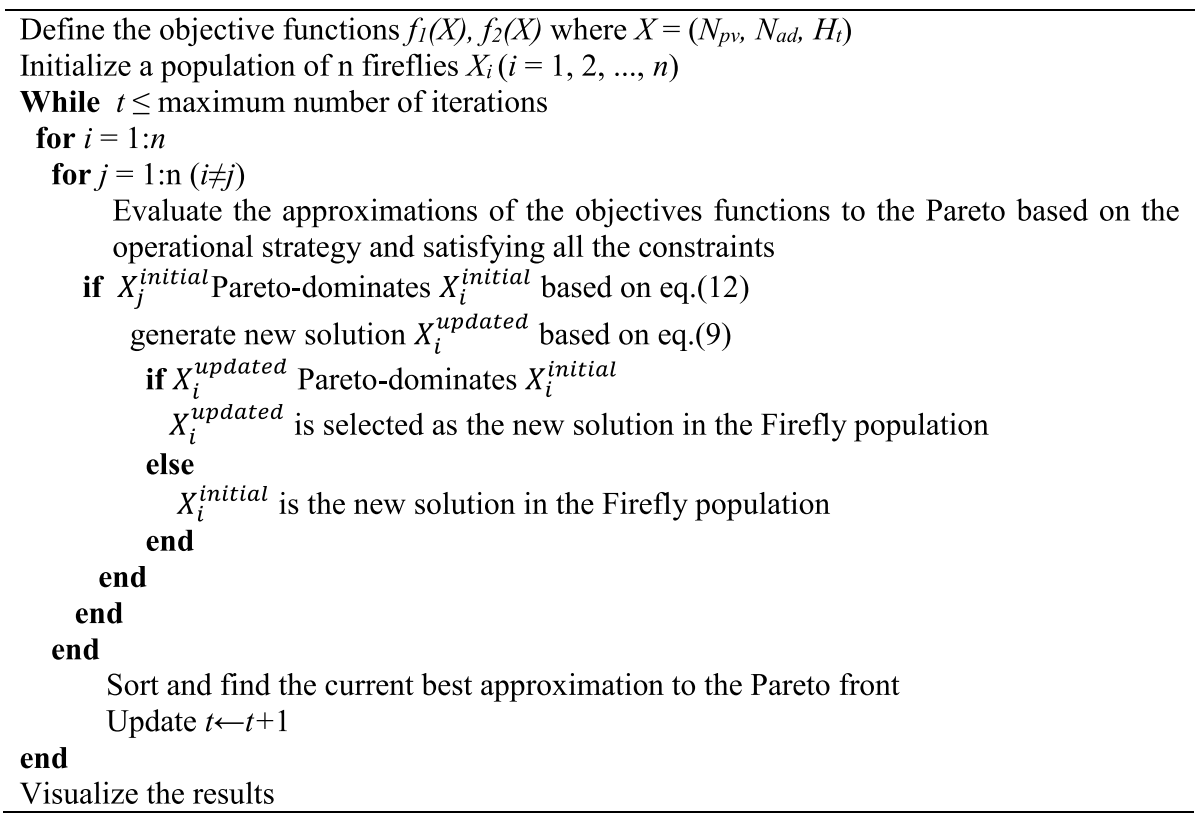


Table 4 Minimum and maximum values of variables to optimize

\begin{tabular}{lcc}
\hline Variables & Minimum & Maximum \\
\hline Number of PV modules $\left(N_{\mathrm{pv}}\right)$ & 1 & 15 \\
Number of autonomy days of reservoir $\left(N_{\mathrm{ad}}\right)$ & 2 & 3 \\
Total dynamic head $\left(H_{\mathrm{t}}\right)$ & 40 & 100 \\
\hline
\end{tabular}

Table 5 Parameters used for simulation

\begin{tabular}{ll}
\hline Designation & Value \\
\hline Type of PV module & BP 3 series 235 W \\
Efficiency of the pump & $70 \%$ \\
Pump nominal running time per day & $8 \mathrm{~h}$ \\
Interest rate & $8 \%$ \\
Annual inflation rate & $2 \%$ \\
\hline
\end{tabular}

the lowest COW is identified through the FA algorithm simulation based on the objective functions and the operational strategy. The pseudo-code of the doubleobjective firefly optimization related to this work is presented in Table 3. The minimum and maximum values of the optimized variables for simulation are given in Table 4. The used parameters for simulation are given in Table 5.

\section{Results and discussion}

The aim of this work is to develop a powerful sizing and optimization method for PV/ water pumping system. The total water demand for the case study is $49.2 \mathrm{~m}^{3} /$ day. The system lifetime is 25 years. Since the system works without energy storage, the pump is supposed to run during the day only for a maximum of $8 \mathrm{~h}$. Pareto front is computed thanks to a double-objective optimization using FA algorithm. Pareto front is very helpful for decision-making concerning the system configuration according to the users priorities because all the solutions on the Pareto front are optimal solutions. This tool is adapted for practical problems. The technical analysis of the system is performed to measure his reliability which is related to the LWSP. The best reliability of the system corresponds to LWSP of $0 \%$. The economic analysis aims to measure the financial accessibility of the system. The economic criterion concerning this study is the COW.

The convergence of the firefly algorithm to find the optimal solution is shown in Fig. 5 According to some papers [33, 35, 38, 39], the FA converges very quickly in less than 80 iterations and less than 50 fireflies. According to Sankalap and Satvir [40], a minimum number of fireflies lead to best results. Computational time also increases when the population size increases [33, 35, 38]. In this work, the simulation is performed with 30 iterations and 100 population size. The stopping criteria are checked with the maximum number of iterations. Figure 5 shows that the convergence of 


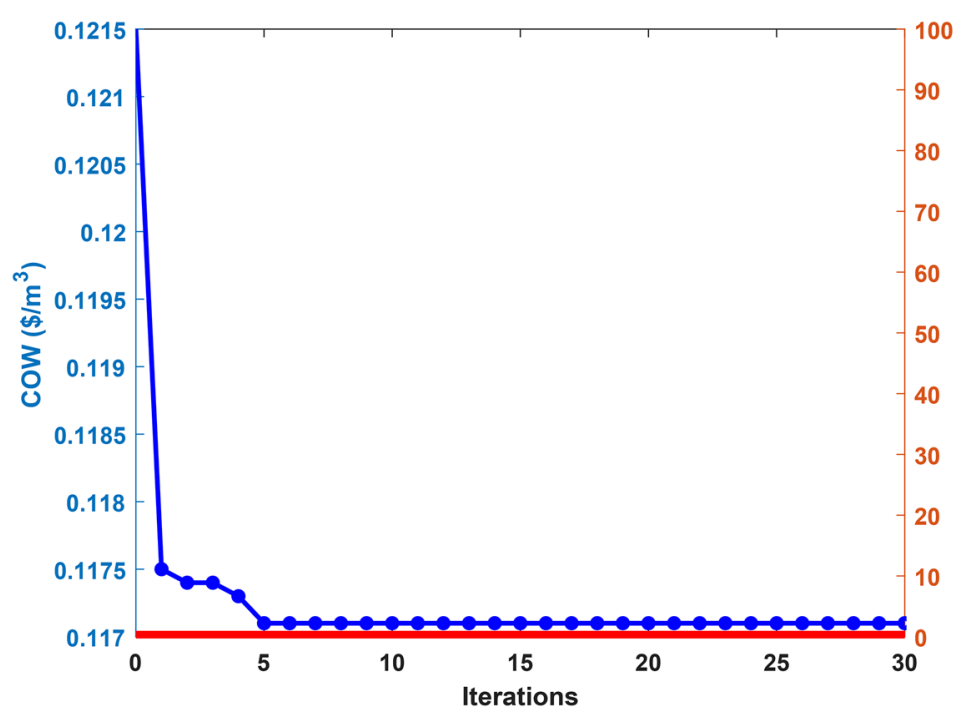

Fig. 5 Convergence of FA to find the optimal solution

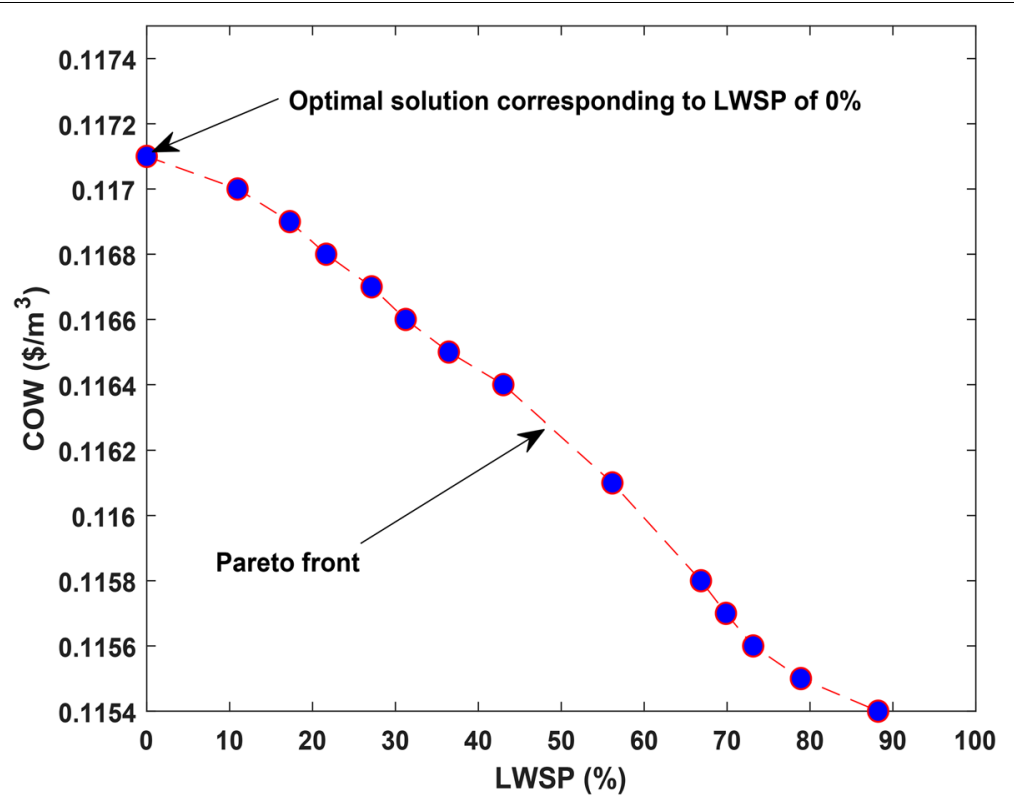

Fig. 6 Pareto front obtained for a double-objective optimization

the FA algorithm to find the best optimal solution corresponding to LWSP of $0 \%$ is obtained from the 5th iteration. This result demonstrates the fast convergence of the FA for multi-objective optimization.

Figure 6 presents a sample of collection of the optimal solutions on the Pareto front for the actual case study concerning the techno-economic analysis. This figure presents the variation in the cost of water (COW) with respect to LWSP. Figure 6 shows that the cost of water increases (and thus the investment cost) when the LWSP decreases, thus improving the reliability of the system results on the increase in his cost. The size 


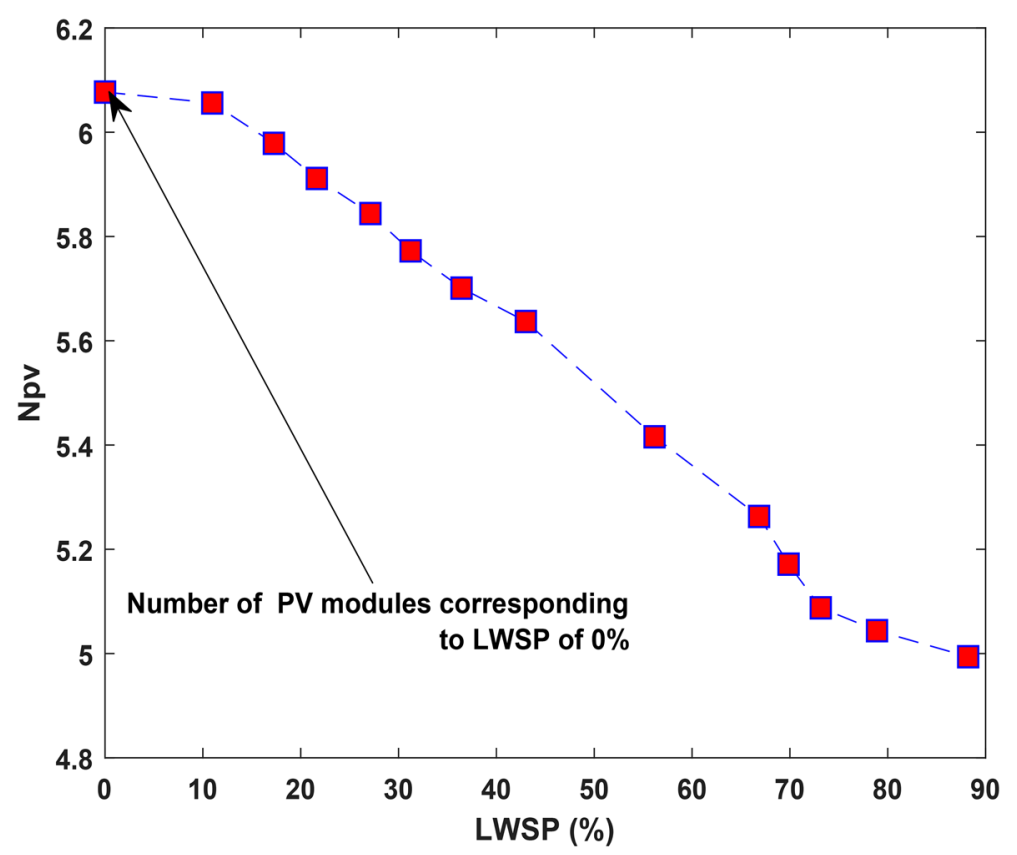

Fig. 7 Variation in number of PV modules on Pareto front

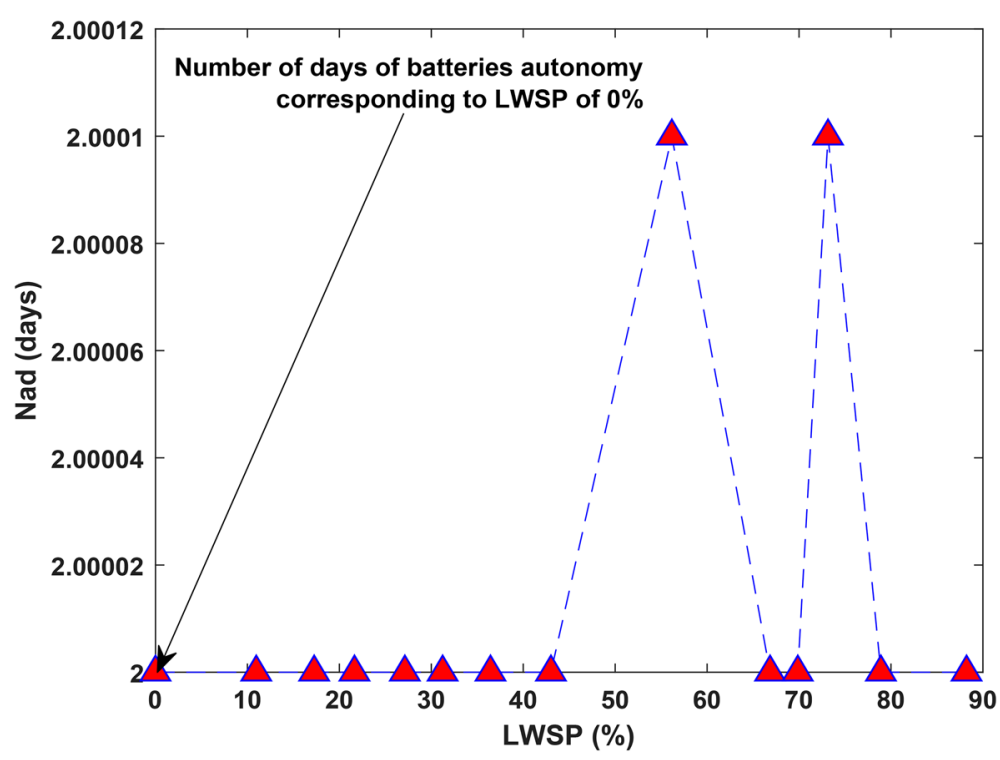

Fig. 8 Variation in the number of days of reservoir autonomy on Pareto front

variation in the PV modules, the variation in the number of days of reservoir water storage autonomy, and the variation in the total dynamic head on the Pareto front are presented, respectively, in Figs. 7, 8 and 9. There is a correspondence on the Pareto front between the points of Fig. 6 with those of Figs. 7, 8 and 9, as shown in Table 6. These points give different optimal configurations of the system with their related cost and reliability. 


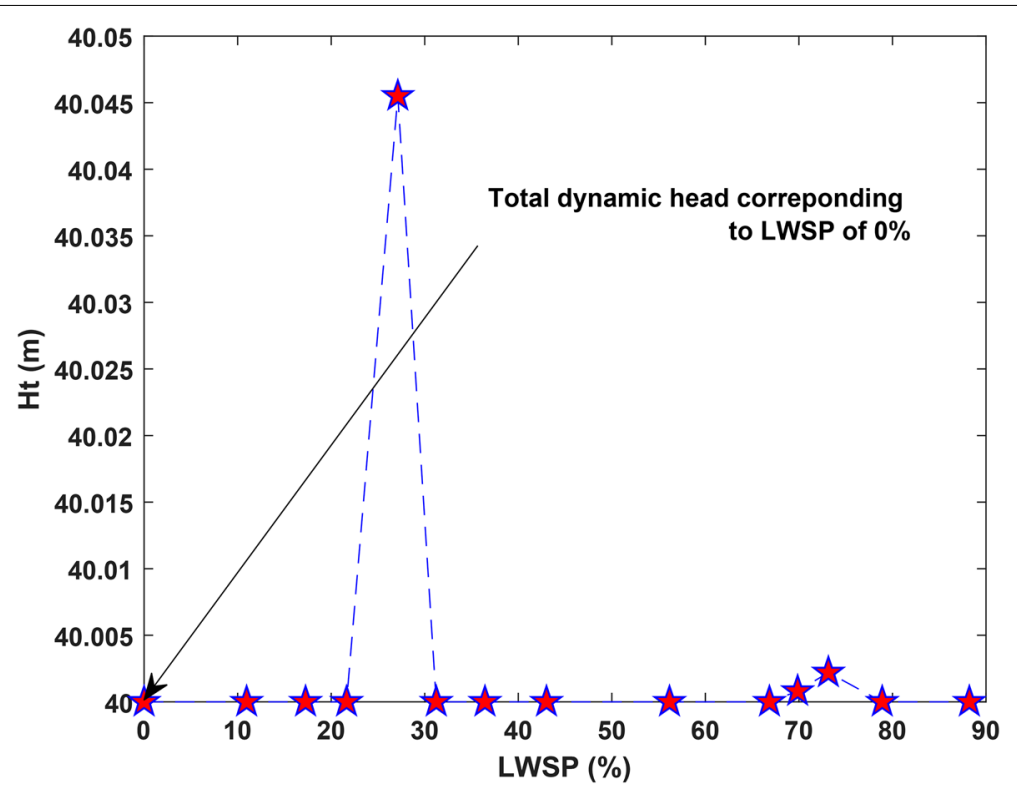

Fig. 9 Variation in the total dynamic head on Pareto front

Table 6 Different optimal configurations of the studied system

\begin{tabular}{lllll}
\hline LWSP (\%) & COW $\left(\mathbf{\$} / \mathbf{m}^{\mathbf{3}}\right)$ & $N_{\mathbf{p v}}$ & $N_{\text {ad }}$ (days) & $H_{\mathbf{t}}(\mathbf{m})$ \\
\hline 0 & 0.1171 & 6.0770 & 2.0000 & 40.0000 \\
10.9589 & 0.1170 & 6.0561 & 2.0000 & 40.0000 \\
17.2603 & 0.1169 & 5.9787 & 2.0000 & 40.0000 \\
21.6438 & 0.1168 & 5.9113 & 2.0000 & 40.0000 \\
27.1233 & 0.1167 & 5.8440 & 2.0000 & 40.0455 \\
31.2329 & 0.1166 & 5.7724 & 2.0000 & 40.0000 \\
36.4384 & 0.1165 & 5.7010 & 2.0000 & 40.0000 \\
43.0137 & 0.1164 & 5.6369 & 2.0000 & 40.0000 \\
56.1644 & 0.1161 & 5.4158 & 2.0001 & 40.0000 \\
66.8493 & 0.1158 & 5.2630 & 2.0000 & 40.0000 \\
69.8630 & 0.1157 & 5.1715 & 2.0000 & 40.0008 \\
73.1507 & 0.1156 & 5.0877 & 2.0001 & 40.0022 \\
78.9041 & 0.1155 & 5.0439 & 2.0000 & 40.0000 \\
88.2192 & 0.1154 & 4.9939 & 2.0000 & 40.0000 \\
\hline
\end{tabular}

Figure 6 shows that for a LWSP of $0 \%$, the COW is $0.1171 \$ / \mathrm{m}^{3}$ corresponding to a total investment cost (including replacement, operation, and maintenance) of 27,180 $\$$. Based on Figs. 7, 8 and 9, the configuration of the system corresponding to this optimal solution is composed by: 6.077 PV modules, 2 days of reservoir water storage autonomy (corresponding to reservoir storage volume of $98.4 \mathrm{~m}^{3}$ ), and the total dynamic head is $40 \mathrm{~m}$. The pump power calculated through Eq. (1) and corresponding to this optimal total dynamic head is $0.958 \mathrm{~kW}$. Thus, considering a solar pump power of $1 \mathrm{~kW}$ is more appropriate. Since the number of PV modules with decimal digits is inappropriate, the number of PV modules to consider will be "7" instead of "6.077." Considering all these approximations, the optimal configuration of the system corresponding to LWSP of $0 \%$ 


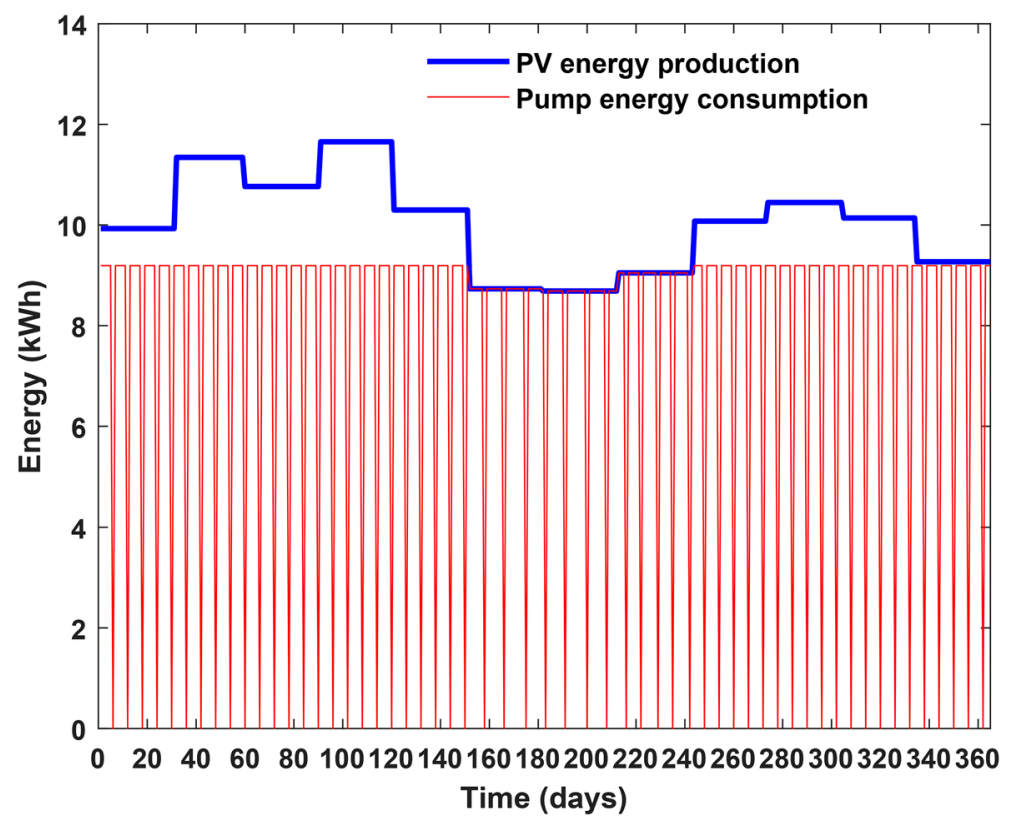

Fig. 10 Comparison between daily variation in energy production and energy consumption over one year for the optimal configuration corresponding to LWSP of $0 \%$

is thus composed by: $7 \mathrm{PV}$ modules, $98.4 \mathrm{~m}^{3}$ of reservoir storage (having 2 days autonomy), $40 \mathrm{~m}$ of total dynamic head, and a solar pump of $1 \mathrm{~kW}$. The COW corresponding this configuration is $0.1185 \$ / \mathrm{m}^{3}$, and the total investment cost is $27,506 \$$.

Figure 10 presents the comparison between the daily variation in the energy production and the energy consumption over one year for the optimal configuration corresponding to LWSP of $0 \%$. It is shown in this figure that for all the days, the energy production is greater or equal than/to the energy consumption. This result demonstrates the good reliability of the designed system because the energy demanded to run the pump is fully satisfied at each moment. Figure 10 shows that the pump energy demand varies with the PV energy production. All the cases where the PV energy production is above the pump energy consumption mean that the pump runs on his maximum permissible power (by referring to the defined operational strategy); this case is mostly represented in Fig. 10. This result demonstrates the great solar energy potential of the studied site.

According to the defined operational strategy, the pump stops to run when the water inside the reservoir reached his maximum level and will only restart to run the next day (since the time interval is in term of days). This is observed in Fig. 11 (which presents the time variation in the pump daily energy consumption for the optimal configuration corresponding to LWSP of $0 \%$ ) where the pump energy consumption is zero for some days. By this time, the water is supplied by the reservoir which has an autonomy of 2 days for the optimal configuration corresponding to LWSP of $0 \%$. Figure 12 presents the distribution over one year (365 days) of the pump running time (in days) with respect to the pump energy consumption. It can be observed in this figure that for 228 days, the pump runs on his maximum allowable power (because the energy supplied at each time interval during these periods mostly corresponds to 


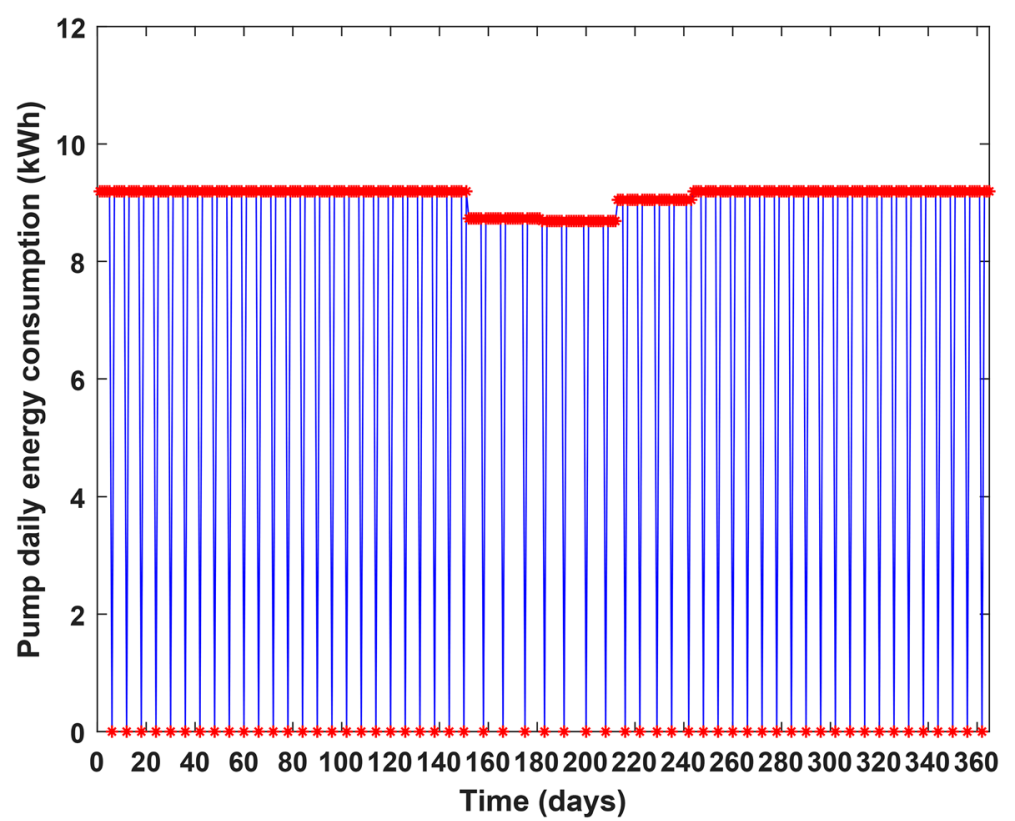

Fig. 11 Time variation in pump daily energy consumption for the optimal configuration corresponding to LWSP of $0 \%$

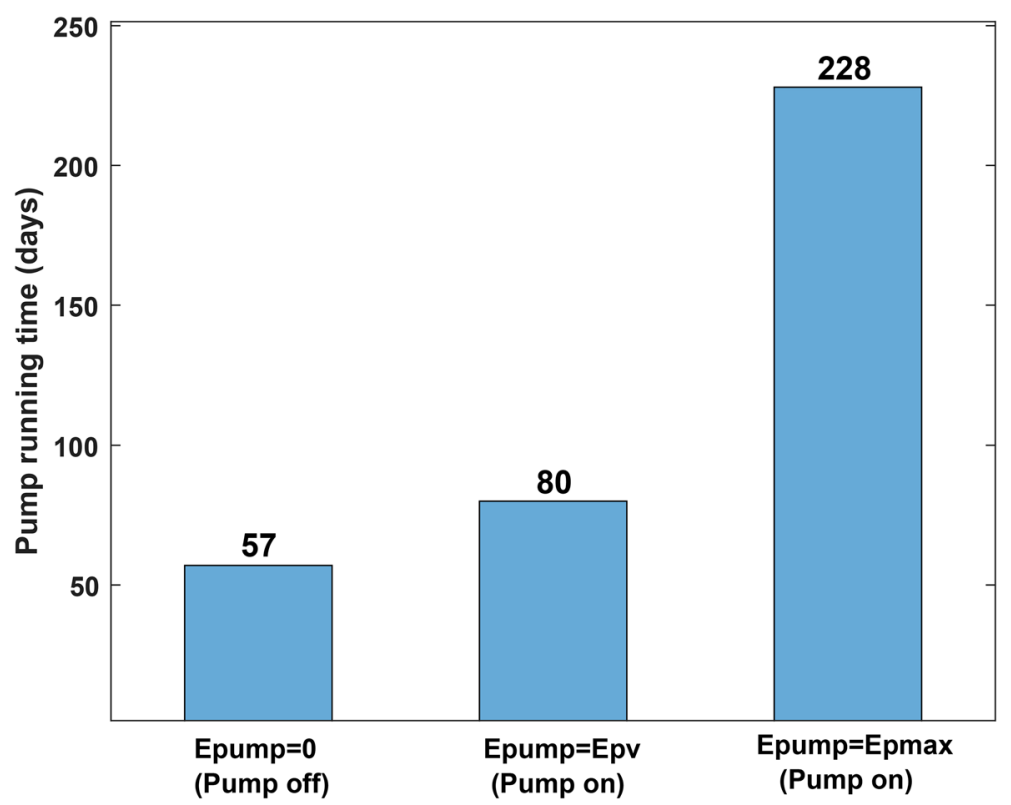

Fig.12 Distribution of Pump running time over one year for the optimal configuration corresponding to LWSP of $0 \%$

the maximum energy admissible by the pump). This result proves once again the great solar energy potential of the studied site. Figure 12 shows that the pump is off for about 57 days (or $456 \mathrm{~h}$ since the daily running time of the pump is set to $8 \mathrm{~h}$ ). During these days, the pump is not working, not because of an energy deficit (since the PV 
energy production is always above the minimum energy demanded by the pump), but because the pump stops to work automatically when the maximum storage capacity of the reservoir is reached, thus avoiding unnecessary pumping water. For over one year (365 days), the pump was supposed to run for $2920 \mathrm{~h}(365 \times 8 \mathrm{~h})$, but according to Fig. 12, his running time is reduced to $2464 \mathrm{~h}(228 \times 8 \mathrm{~h}+80 \times 8 \mathrm{~h})$. The reduction in the pump running time is proportional to the volume of the reservoir water storage. This reduction is very helpful to increase the pump lifetime.

Figure 13 presents the total energy production, energy consumption and surplus of energy production, for each month of the year, corresponding to LWSP of $0 \%$. This figure confirms that the generated energy is enough sufficient to respond to the energy demand. Considering surplus of energy production is recommended when sizing a PV system. A system sized with such kind of configuration will be able to respond efficiently to load demand even in unfavorable weather conditions.

Figure 14 presents for each day of the year a comparison between the water supply and the water demand for the optimal configuration corresponding to LWSP of 0\%. Figure 14 shows that the volume of water inside the reservoir is always above the volume of the water demand. The water demand is totally satisfied for all the days of the year. This result demonstrates one again the good reliability of the designed system.

Figure 15 presents the contribution of each key component of the system on the total investment cost. The most costly component is attributed to the storage subsystem which represents $61 \%$ of the total investment cost of the system, followed by the pump representing $30 \%$ of the NPC. The rest of the total investment cost is attributed to the PV subsystem which represents only $9 \%$ of the NPC.

The sensitivity analysis is done by considering the impact of the variation in the optimized parameters on the system behavior. Table 7 presents the influence of the PV

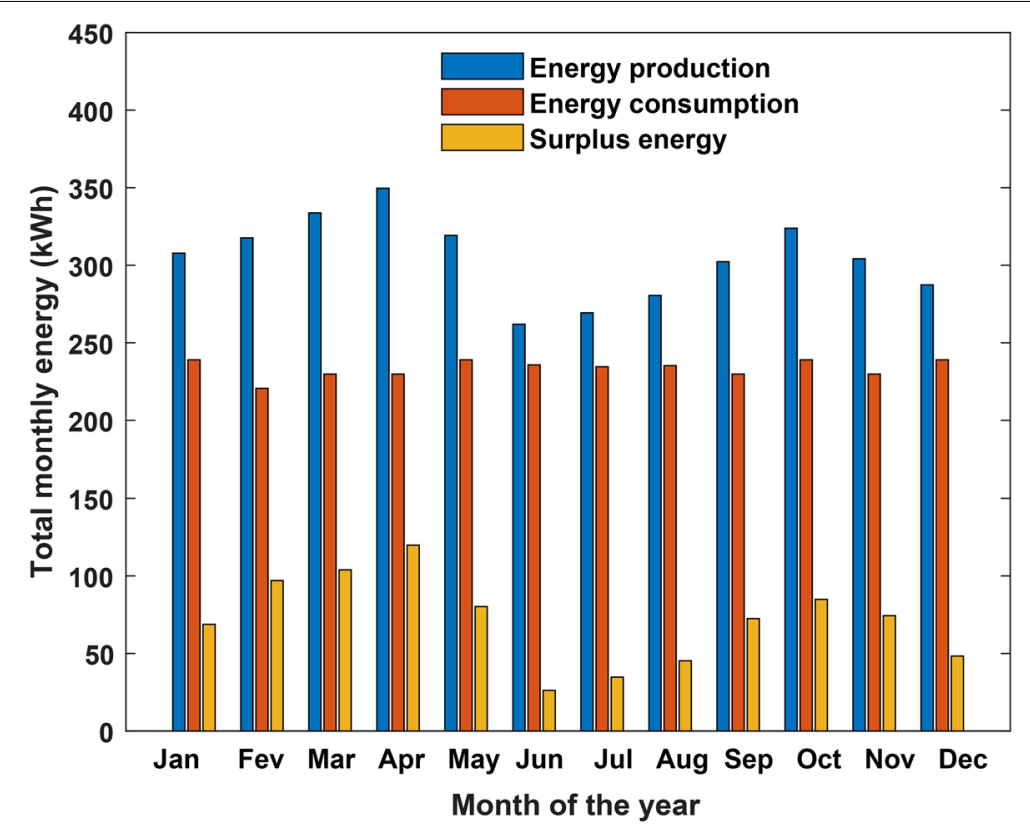

Fig. 13 Graphical representation of the total monthly energy generation, energy consumption and surplus of energy for the optimal configuration corresponding to LWSP of 0\% 


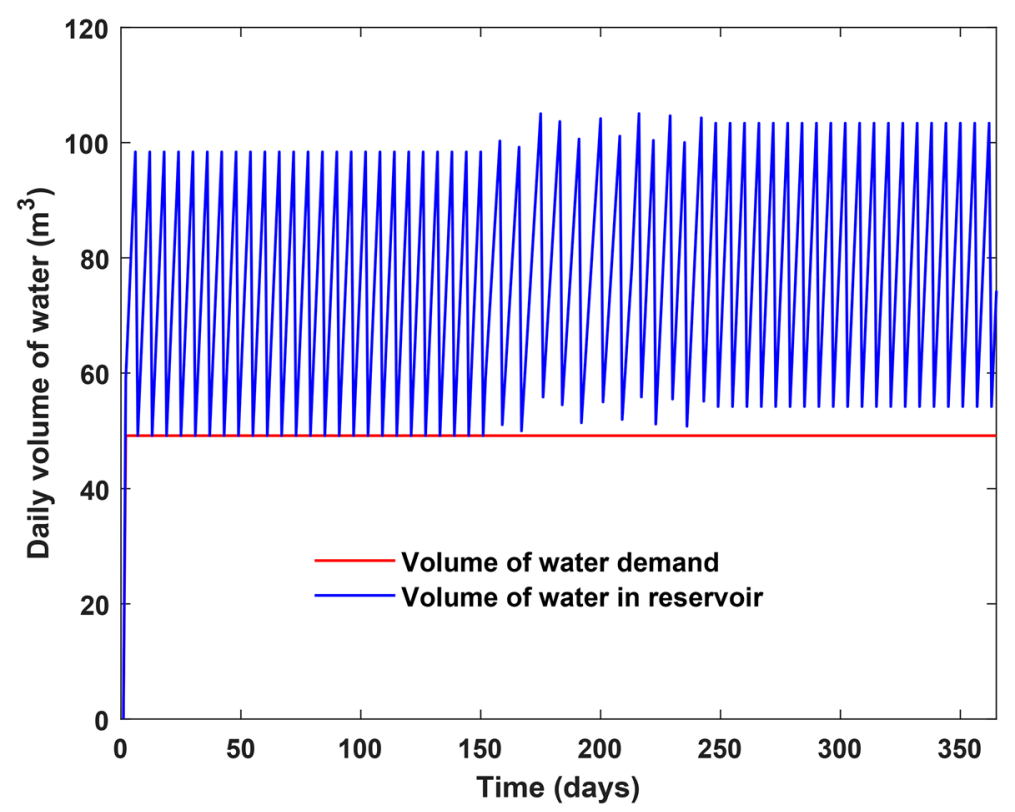

Fig. 14 Comparison between time variation in water supply and water demand for the optimal configuration corresponding to LWSP of $0 \%$

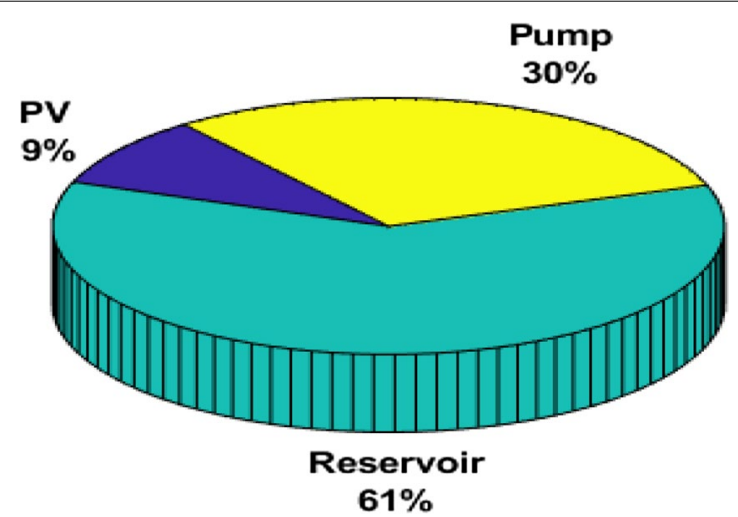

Fig. 15 Contribution of each key component of the system on the total investment cost for the optimal configuration corresponding to LWSP of $0 \%$

Table 7 Influence the PV modules size on the cost and reliability of the system

\begin{tabular}{|c|c|c|c|c|}
\hline$N_{p v}$ & $N_{\text {ad }}$ (days) & $H_{t}(\mathrm{~m})$ & LWSP (\%) & $\operatorname{cow}\left(\$ / m^{3}\right)$ \\
\hline 5 & 2 & 40 & 86.8493 & 0.1154 \\
\hline 6 & 2 & 40 & 26.8493 & 0.1170 \\
\hline 7 & 2 & 40 & 0 & 0.1185 \\
\hline 9 & 2 & 40 & 0 & 0.1215 \\
\hline 11 & 2 & 40 & 0 & 0.1246 \\
\hline
\end{tabular}


Table 8 Influence of reservoir water storage size on the cost and reliability of the system

\begin{tabular}{lllll}
\hline$N_{\mathbf{p v}}$ & $N_{\text {ad }}$ (days) & $H_{\mathbf{t}}(\mathbf{m})$ & LWSP (\%) & COW $\mathbf{( \$ / \mathbf { m } ^ { \mathbf { 3 } } )}$ \\
\hline 7 & 1 & 40 & 83.8356 & 0.0825 \\
7 & 2 & 40 & 0 & 0.1185 \\
7 & 3 & 40 & 0 & 0.1545 \\
\hline
\end{tabular}

Table 9 Influence of total dynamic head on the cost and reliability of the system

\begin{tabular}{lllll}
\hline$N_{\mathbf{p v}}$ & $N_{\text {ad }}$ (days) & $H_{\mathbf{t}}(\mathbf{m})$ & LWSP (\%) & COW $\mathbf{( \$ / \mathbf { m } ^ { \mathbf { 3 } } )}$ \\
\hline 7 & 2 & 20 & 0 & 0.1185 \\
7 & 2 & 30 & 0 & 0.1185 \\
7 & 2 & 40 & 0 & 0.1185 \\
7 & 2 & 50 & 58.0822 & 0.1185 \\
7 & 2 & 60 & 99.7260 & 0.1185 \\
\hline
\end{tabular}

generator size on the cost and reliability of the system. It comes out that the COW increases when the size of the PV generator increases (the increase in $N_{\mathrm{pv}}$ ), whereas the reliability of the system decreases when the size of the PV generator decreases (the decrease in $N_{\text {pv }}$ ). Similarly in Table 8 which presents the influence of the reservoir storage size on the cost and reliability of the system, the COW increases when the size of the reservoir storage increases (the increase in $N_{\text {ad }}$ ), whereas the reliability of the system decreases when the size of the reservoir storage decreases (the decrease in $N_{\text {ad }}$ ). Thus, the size of the PV generator and the size of the reservoir storage influence the system both technically and economically. Table 9 presents the influence of the total dynamic head on the cost and reliability of the system. It comes out that the COW does not change when the size of the total dynamic head increases. However, the reliability of the system decreases when the total dynamic head increases. Thus, the total dynamic head only influences the system technically but does not have any influence on his economic aspect. These obtained results on sensitivity analysis of a water pumping system are somewhat similar to those obtained in the literature. Meunier et al. [7], for example, performed the sensitivity analysis of a Photovoltaic water pumping system by studying the influences of some parameters on a proposed PV/water pumping system. Their results have shown that the PV module, the pump, and the reservoir water storage have the greatest impact on the technical aspect of the system, whereas the total dynamic head has the highest influence on the economic optimization of the studied system considered. Bouzidi et al. [41] have also demonstrated that the size of the reservoir storage has an influence on the reliability and on the system sizing and therefore must have a great consideration.

The validation of the optimal sizing of the proposed PV/water pumping system is done by considering Fig. 16 which presents the variation in the pump nominal power with respect to the pump efficiency based on Eq. (1). Indeed, concerning this study, the optimal configuration of the system $\left(N_{\mathrm{pv}}=7, V_{\max }=94.3 \mathrm{~m}^{3}, H_{\mathrm{t}}=40 \mathrm{~m}, P_{\text {pump }}=0.958 \mathrm{~kW}\right.$ approximated to $1 \mathrm{~kW}$ ) has been determined for a water flow rate of $6.15 \mathrm{~m}^{3} / \mathrm{h}$ and a pump efficiency of 70\%. According to Ref. [42], a water flow rate of $6.15 \mathrm{~m}^{3}$ could be 


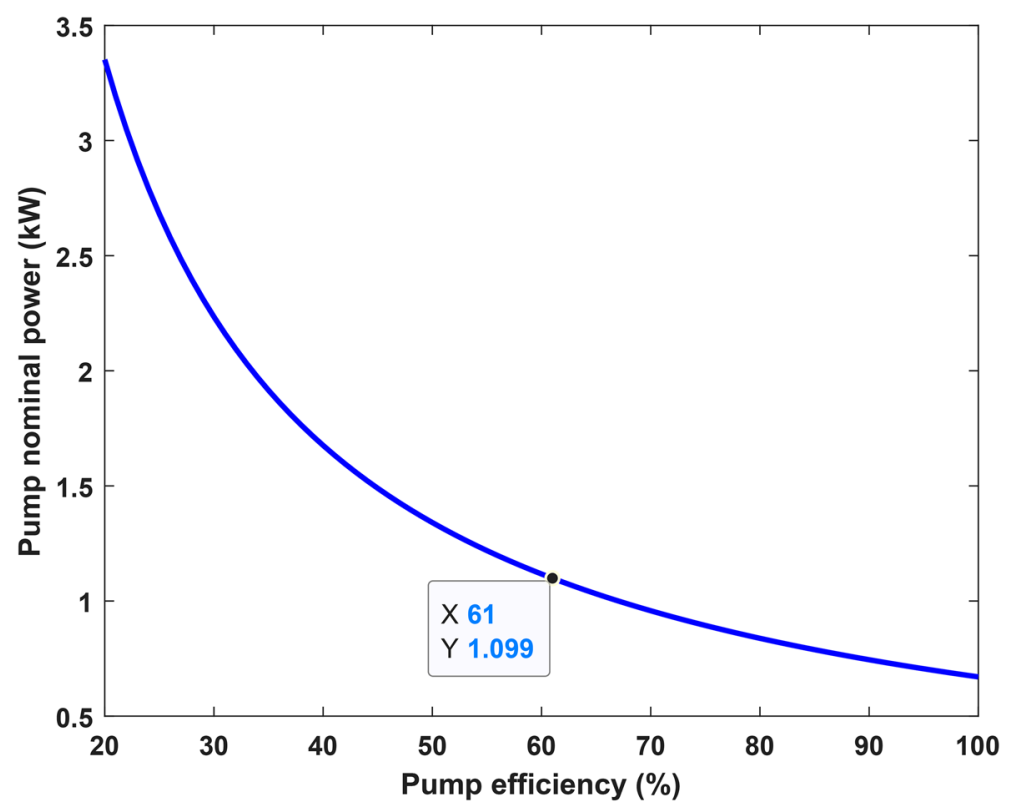

Fig. 16 Influence of pump efficiency on the nominal power of the pump for a water flow rate of $6.15 \mathrm{~m}^{3}$ and a total dynamic head of $40 \mathrm{~m}$

Table 10 Influence of the pump efficiency variation on the system reliability and configuration

\begin{tabular}{llllll}
\hline Efficiency (\%) & $N_{\mathbf{p v}}$ & $N_{\text {ad }}$ (days) & $H_{\mathbf{t}}(\mathbf{m})$ & LWSP $(\%)$ & COW $\left(\mathbf{\$} / \mathbf{m}^{\mathbf{3}}\right)$ \\
\hline 70 & 7 & 2 & 40 & 0 & 0.1185 \\
61 & 7 & 2 & 40 & 19.1781 & 0.1185 \\
61 & 8 & 2 & 40 & 0 & 0.1200 \\
\hline
\end{tabular}

obtained for a total dynamic head of $38 \mathrm{~m}$ by a motor pump having a nominal power of $1.1 \mathrm{~kW}$ and an efficiency of $61 \%$. Figure 16 shows that the pump power of the optimal configuration obtained changes to $1.099 \mathrm{~kW}$ (which can be approximated to $1.1 \mathrm{~kW}$ ) when the pump efficiency changes to $61 \%$. Note that this result is obtained for a total dynamic head of $40 \mathrm{~m}$ which is near to $38 \mathrm{~m}$. Thus, the obtained results confirmed those given in the literature. Table 10 shows that the variation in the pump efficiency affects the reliability of the system, imposing the change of the system configuration (the number of PV module has changed in the present case). The influence of the pump efficiency on the sizing and the reliability of a PV/water pumping system is confirmed in the literature by Meunier et al. [7].

\section{Conclusion}

In this paper, a techno-economic analysis of a stand-alone PV/water pumping system for various applications has been realized for a case study in Cameroon. A double-objective optimization has been performed for the optimal design of the system configuration. Different optimal configurations are obtained according to the related COW and LWSP. The objective was to determine a configuration with LWSP of $0 \%$ and with low COW. The optimal configuration corresponding to these criteria is composed by $7 \mathrm{PV}$ modules of $235 \mathrm{~W}_{\mathrm{C}^{\prime}}$ 
a reservoir volume of $98.4 \mathrm{~m}^{3}$, a total dynamic head of $40 \mathrm{~m}$, and a pump nominal power of $1 \mathrm{~kW}$ having an efficiency of $70 \%$. Such configuration results on a cost of water of $0.1185 \$$ / $\mathrm{m}^{3}$. The influences of the variations in some parameters on the system configuration have also been discussed in this paper. It is obvious that the PV/water pumping system could be very advantageous financially and even technically, and therefore suitable for rural and remote areas.

Many optimal sizing tools pre-define the size of some system components such as the pump power or the total dynamic head. In this article, the sizes of all system components are not pre-defined. They are optimized and determined by numerical simulation using the proposed operational strategy and the firefly optimization algorithm. This research paper is a powerful sizing tool which could be helpful for designers and users of PV/water pumping systems. It has shown the effectiveness of the proposed modeling based on firefly algorithm for the optimal design of PV/water pumping systems.

\section{Abbreviations}

PV: Photovoltaic; NOCT: Nominal operating cells temperature $\left({ }^{\circ} \mathrm{C}\right)$; SOC: State of charge of water in the reservoir; LWSP: Loss of water supply probability; COW: Cost of water; FA: Firefly algorithm; NPC: Net present cost.

\section{Symbols}

$N_{\text {pv: }}$ : Number of photovoltaic modules; $P_{\text {pvv }}$ : Photovoltaic power $(W) ; P_{\text {pvrref: }}$ Photovoltaic power at reference condition $\left(25^{\circ} \mathrm{C}\right.$ or $\left.298 \mathrm{~K}\right)(\mathrm{W}) ; T_{\mathrm{a}}$ : Ambient temperature $\left({ }^{\circ} \mathrm{C}\right) ; \mathrm{G}$ : Solar radiation $\left(\mathrm{kWh} / \mathrm{m}^{2}\right) ; G_{\text {ref }}$ Irradiance at reference condition (W/ $\left.\mathrm{m}^{2}\right) ; G_{\text {NOCT: }}$ Solar radiation at NOCT $\left(\mathrm{kWh} / \mathrm{m}^{2}\right) ; T_{c}$ : Cell Temperature $\left({ }^{\circ} \mathrm{C}\right.$ or $\left.\mathrm{K}\right) ; T_{\text {c,ref: }}$ Cell Temperature at reference condition $\left(25^{\circ} \mathrm{C}\right.$ or $\left.298 \mathrm{~K}\right)$; $E_{\mathrm{pv}}$ : Photovoltaic daily energy production; Iter: Iteration; Iter_max: Maximum number of iterations; $Q_{\text {pump: }}$ Water flow of the pump $\left(\mathrm{m}^{3} / \mathrm{s}\right) ; P_{\text {pump: }}$ : Pump power consumption; $E_{\text {pump: }}$ : Pump daily energy consumption; $E_{\text {supply: }}$ Energy supplied to load; $V_{\text {demand: }}$ Volume of water demand; $V_{\text {pumped: }}:$ Volume of pumped water; $V_{R}:$ Volume of water in the reservoir; $\mathrm{N}_{\mathrm{ad}}$ : Number of autonomy days of the reservoir; $H_{\mathrm{t}}$ : Total manometric height; Cost ${ }_{\mathrm{pv}}$ : Cost of photovoltaic modules; Cost $_{\text {reservoir: Cost of reservoir; Cost }}$ pump: Cost of pump.

\section{Greek symbols}

$a$ : Temperature coefficient of short-circuit current $(\mathrm{A} / \mathrm{K}) ; \rho$ : Water density $\left(\mathrm{Kg} / \mathrm{m}^{3}\right)$; $\eta$ : Pump efficiency; $\$$ : US dollar.

\section{Subscripts}

max: Maximum; min: Minimum

\section{Acknowledgements}

Not applicable.

\section{Authors' contributions}

Both RZF and HB proposed the idea. RZF did the numerical implementation and simulations. Both RZF and HB contributed in the writing part. RZF and VD revised the manuscript. All authors read and approved the final manuscript.

Funding

Not applicable.

\section{Availability of data and material}

All the data are included in the manuscript's tables.

\section{Declarations}

Competing interests

The authors declare that they have no competing interests.

\section{Author details}

${ }^{1}$ Faculty of Mines and Petroleum Industries, University of Maroua, P.O. Box 46, Maroua, Cameroon. ${ }^{2}$ Laboratory of Energy Research, Institute for Geological and Mining Research, P.O Box 4110, Yaoundé, Cameroon. ${ }^{3}$ Department of Power Systems, Faculty of Power Engineering, University Politehnica of Bucharest, Splaiul Independentei, No 313, District 6, 060042 Bucharest, Romania. 


\section{References}

1. Priyanka S, Prerna G (2019) Grid interfaced solar water pumping system with improved space vector modulated direct torque control. Ain Shams Eng J 11:1149-1162

2. Joao VMC, Luis Felipe MT (2014) Implementation of a high-efficiency, high-lifetime, and low-cost converter for an autonomous photovoltaic water pumping system. IEEE Trans Ind Appl 50:631-641

3. Abdolzadeh M, Ameri M (2011) Mehrabian MA (2011) Effects of water spray over the photovoltaic modules on the performance of a photovoltaic water pumping system under different operating conditions. Energy Sources 33:1546-1555

4. Kim J, Kim C, Kim J (2011) A regulated charge pump with a low-power integrated optimum power point tracking algorithm for indoor solar energy harvesting. IEEE Trans Circuits Syst 58:12

5. Azadeh K (2010) The effects of nominal power of array and system head on the operation of photovoltaic water pumping set with array surface covered by a film of water. Renew Energy 35:1098-1102

6. Odeh I, Yohanis YG, Norton B (2006) Influence of pumping head, insolation and PV array size on PV water pumping system performance. Sol Energy 80:51-64

7. Meunier S, et al (2019) Modelling and optimal sizing of photovoltaic water pumping systems-Sensitivity analysis. In: 2019 Fourteenth international conference on ecological vehicles and renewable energies (EVER). IEEE

8. Brahmi A et al (2018) Design and optimal choice of a $1.5 \mathrm{~kW}$ photovoltaic pumping system for irrigation purposes. AIP Conf Proc 2056:020004

9. Raghuwanshi SS, Vikas K (2018) Sizing and modelling of stand-alone photovoltaic water pumping system for irrigation. Energy Environ 29:473-491

10. Bora B, Prasad B, Sastry OS, Kumar A, Bangar M (2017) Optimum sizing and performance modeling of Solar Photovoltaic (SPV) water pumps for different climatic conditions. Sol Energy 155:1326-1338

11. Yahia B, Arab AH, Azoui B (2011) Optimal sizing of photovoltaic pumping system with water tank storage using LPSP concept. Sol Energy 85:288-294

12. Dagtekin M (2014) A study of techno-economic feasibility analysis of solar photovoltaic (PV) power generation in the province of Adana in Turkey. Energy Explor Exploit 32:719-735

13. Lal S, Kumar P, Rajora R (2013) Techno-economic analysis of solar photovoltaic based submersible water pumping system for rural areas of an Indian state Rajasthan. Sci J Energy Eng 1:1-4

14. Kumar A, Kandpal TC (2007) Potential and cost of $\mathrm{CO}_{2}$ emissions mitigation by using solar photovoltaic pumps in India. Int J Sustain Energy 26:159-166

15. Purohit P, Kandpal TC (2011) Solar photovoltaic water pumping in India: a financial evaluation. Int J Ambient Energy 26:135-146

16. Najet R et al (2015) Implementation of photovoltaic water pumping system with MPPT controls. Front Energy 9:187-198

17. Muamer MS, Tariq I (2017) Dynamic modeling, control, and analysis of a solar water pumping system for Libya. J Renew Energy 2017:1-13

18. Chafia S, Djamila R (2015) Control of photovoltaic water pumping system. J Electr Eng 15:339-344

19. Biji G (2012) Modelling and simulation of PV based pumping system for maximum efficiency. In: International conference on power, signals, controls and computation, IEEE pp 1-6.

20. Ibrahim SMA et al (2020) Comprehensive design tool for sizing solar water pumping system in Egypt. Appl Sol. Energy 56:18-29

21. Muhsen DH et al (2017) Techno-economic study and optimal sizing of a stand-alone photovoltaic water pumping system. Int Trans Electr Energ Syst. 27:e2355

22. Chennaif $M$, et al (2019) Electric system cascade analysis for optimal sizing of an autonomous photovoltaic water pumping system. In: International conference on smart Information \& communication technologies, SmartICT 2019 : advances in smart technologies applications and case studies pp 282-290

23. Olcan C (2015) Multi-objective analytical model for optimal sizing of stand-alone photovoltaic water pumping systems. Energy Convers Manag 100:358-369

24. Rakhi Sharma R, Sharma S, Tiwari S (2020) Design optimization of solar PV water pumping system. Mater Today Proc 21:1673-1679

25. Fadaee M, Radzi MAM (2012) Multi-objective optimization of a stand-alone hybrid renewable energy system by using evolutionary algorithms: a review. Renew Sustain Energy Rev 16:3364-3369

26. Ma T et al (2015) Pumped storage-based standalone photovoltaic power generation system: modeling and technoeconomic optimization. Appl Energy 137:649-659

27. Mahmoudimehr J, Shabani M (2018) Optimal design of hybrid photovoltaic-hydroelectric standalone energy system for north and south of Iran. Renewable Energy 115:238-251

28. Yang H, Zhou W, Lu L, Fang Z (2008) Optimal sizing method for stand-alone hybrid solar-wind system with LPSP technology by using genetic algorithm. Sol Energy 82:354-367

29. Zieba Falama R et al (2021) A solution to the problem of electrical load shedding using hybrid PV/battery/gridconnected system: the case of households' energy supply of the northern part of Cameroon. Energies 14(10):2836

30. Abdelkader A, Rabeh A, Ali DM, Mohamed J (2018) Multi-objective genetic algorithm based sizing optimization of a stand-alone Wind/PV power supply system with enhanced battery/supercapacitor hybrid energy storage. Energy 163:351-363

31. Mahesh A, Sandhu KS (2020) A genetic algorithm based improved optimal sizing strategy for solar-wind-battery hybrid system using energy filter algorithm. Front Energy 14(1):139-151

32. Chandel SS, Nagaraju NM, Chandel R (2015) Review of solar photovoltaic water pumping system technology for irrigation and community drinking water supplies. Renew Sustain Energy Rev 49:1084-1099

33. Yang XS (2010) Firefly algorithm, stochastic test functions and design optimization. Int J Bio-Inspir Comput 2(2):78-84

34. Yang XS (2014) Nature-inspired optimization algorithms. Elsevier Insight 
35. Yang XS (2009) Firefly algorithms for multimodal optimization, International symposium on stochastic algorithms. Springer, Berlin, Heidelberg, pp 169-178

36. Yang XS (2013) Multiobjective firely algorithm for continuous optimization. Eng Comput 29(2):175-184

37. https://re.jrc.ec.europa.eu/pvg_tools/fr/\#PVP (accessed on 07.04.2021).

38. Yang XS (2010) Nature-inspired metaheuristic algorithms. Luniver press, Beckington, UK

39. Łukasik S, Żak S (2009) Firefly algorithm for continuous constrained optimization tasks. In: International conference on computational collective intelligence. Springer, Berlin, Heidelberg, pp 97-106

40. Arora S, Singh S (2013) The firefly optimization algorithm: convergence analysis and parameter selection. Int J Comput Appl 69(3):48-55

41. Bouzidi B (2013) New sizing method of PV water pumping systems. Sustain Energy Technol Assess 4:1-10

42. https://shop.ksb.com/ims_docs/E8/E8559C48F243AF74E10000009110CDB4.pdf, p 30. Accessed 19 May 2021

\section{Publisher's Note}

Springer Nature remains neutral with regard to jurisdictional claims in published maps and institutional affiliations.

\section{Submit your manuscript to a SpringerOpen ${ }^{\circ}$} journal and benefit from:

Convenient online submission

- Rigorous peer review

Open access: articles freely available online

- High visibility within the field

- Retaining the copyright to your article

Submit your next manuscript at $\gg$ springeropen.com 